A IMPORTÂNCIA DA LEITURA E DA ESCRITA COMO FORMA DE (RE) SOCIALIZAR OS ALUNOS DA MODALIDADE DE EDUCAÇÃO DE JOVENS E ADULTOS DO ENCINO MÉDIO DA CIDADE SÃO LUÍS NO PRESÍDIO FEMININO E MASCULINO

Por Rachel Bonfim da Silva

BOAS PRÁTICAS 


\section{A IMPORTÂNCIA DA LEITURA E DA ESCRITA COMO FORMA DE (RE)SOCIALIZAR OS ALUNOS DA MODALIDADE DE EDUCAÇÁO DE JOVENS E ADULTOS DO ENSINO MÉDIO DA CIDADE DE SÃO LUÍS NO PRESÍDIO FEMININO E MASCULINO}

THE IMPORTANCE OF READING AND WRITING AS A WAY OF (RE) SOCIALIZING THE STUDENTS OF THE MODALITY OF EDUCATION OF YOUNG PEOPLE AND ADULTS OF THE

HIGH SCHOOL OF THE CITY OF SÃO LUÍS IN THE FEMALE AND MALE PRISON.

Por Rachel Bonfim da Silva

Pedagogal Quimica Licenciada/Psicopedagoga/Especialista em Metodologia do Ensino Superior/Supervisora do Estado lotada na escola da EJA "CE Estado do Pará"/Pedagoga da Aeronáutica prestando serviço na Defensoria Pública da União

rachel.silva@dpu.def.br

\section{RESUMO}

Este trabalho apresenta uma pesquisa sobre a escrita e a leitura dos alunos da Educação de Jovens e Adultos no presídio feminino e masculino no estado do Maranhão através da realização do $1^{\circ}$ Concurso de Redaçáo da Defensoria Pública da União no Brasil em todas as capitais com o Título: Eu tenho direito e a DPU está comigo. Teve-se como objetivo geral: analisar de forma crítica e reflexiva a pesquisa, metodologia e o resultado deste trabalho que culminou em duas premiaçóes em $1^{\circ}$ lugar, sendo uma aluna do presídio feminino e outro aluno matriculado numa escola regular ambos da modalidade EJA. Os objetivos específicos foram demonstrar as funçóes da Defensoria Pública da União e incentivar os alunos escreverem uma redação sobre seus direitos. Diante dos resultados obtidos, percebeu-se que os alunos que tinham mais práticas com as leituras e as escritas tiveram melhor êxito nas suas redaçóes.

Palavras-chave: Leitura. Escrita. Educação de Jovens e Adultos. Defensoria Pública da União. 


\section{INTRODUÇÃO}

Segundo Foucambert ${ }^{1}$, a leitura significa ser questionado pelo mundo e por si mesmo. Significa que certas respostas podem ser encontradas na escrita, significa poder ter acesso à escrita, significa construir uma resposta que integra parte de novas informaçóes ao que já se é.

Partindo do descrito acima, concorda-se que não basta somente permitir o acesso dos alunos à leitura e à escrita: torna-se imprescindível que esse se torne leitor e produtor de textos e mais conhecedor dos seus direitos, o que acabou sendo nosso objeto de pesquisa.

A leitura e a escrita são fatores fundamentais para a inserção do ser humano na atual sociedade. As cobranças por esses dois elementos tem sido cada vez mais acirrado para os jovens e os adultos na escola e no mercado de trabalho diariamente. $\mathrm{O}$ ato de ler pode fornecer ao leitor o acesso às informaçóes, á ampliação do vocabulário, o desenvolvimento da criticidade e o interesse na busca pelo conhecimento sobre os assuntos mais variados, que além de instigar o leitor a pensar e conhecer criticamente sobre diversas questóes pode impulsionar suas relaçóes sociais e fazer com que estes conheçam e desfrutem dos seus direitos. Daí a importância dessa pesquisa realizada com esses alunos e o concurso feito por estes nessa modalidade de ensino.

A leitura é fundamentalmente um ato cognitivo, o que significa que a percepção que se tem da tarefa de ler e dos seus objetivos desempenha um papel determinante, pois é esta compreensão que vai tornar operacionais e eficazes as outras competências para a leitura. Assim, um bom leitor é aquele que, ao fomentar as operaçóes de tratamento linguístico ao nível lexical e sintático de forma automática, vai, também, focar a sua atenção para a construção de um modelo de texto, interpretando-o.

Ler é descodificar, extrair o significado da escrita, daí que a leitura seja vista como um processo interativo entre o leitor e o texto, por meio do qual o primeiro reconstrói o significado do segundo. Consequentemente através de uma leitura informativa e formativa, o individuo poderá aprimorar sua escrita, desenvolvendo-a com mais coesão e conhecimento cientifico, cultural, entre outros, composta por informaçóes pertinentes a um determinado assunto.

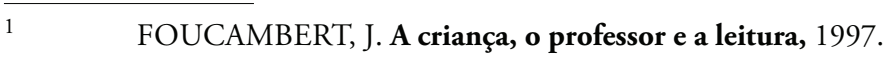


De acordo com Travaglia ${ }^{2}$, se considerarmos a linguagem como um código conhecido, preestabelecido e dominado pelos falantes, deve-se também que a linguagem é um ato social, ou seja, assim acontece a comunicação efetiva. A linguagem é, portanto, considerada como processo de interaçáo social do individuo dentro do seu contexto comunicativo.

A escola vem produzindo grande quantidade de leitores que são capazes de identificar qualquer texto, porém, com enorme dificuldade para compreender o que leem. Entendese que o processo de leitura indica que não se deve ensinar a ler por meio de práticas centradas na decodificação. Propóe-se que se deve fazer o contrário, ou seja, oferecer aos alunos inúmeras oportunidades de aprenderem a ler, usando os procedimentos que os bons leitores utilizam:

Um leitor competente é alguém que, por iniciativa própria, é capaz de selecionar, dentre os trechos que circulam socialmente, aqueles que podem atender a uma necessidade sua. Que consegue utilizar estratégia de leitura adequada para abordá-los de forma a atender a essa necessidade. ${ }^{3}$

Sobre o processo de escrita, alguns autores apresentam um mesmo consenso, em se tratando da capacidade de criação ou (re) criação, por parte de que estar produzindo um texto. Conforme Luria e Leontiev ${ }^{4}$, “[...] a criança, adolescentes, jovens e adultos precisam entender que a escrita é um sistema simbólico de representação da realidade, que não tem significado em si, mas representa um outro contexto [...]”.

A leitura é, ainda, vista como um processo interativo porque diferentes leitores extraem níveis de informação diversificados sobre o mesmo texto, pois possuem níveis de conhecimento diferentes em relação ao tema de que trata o texto, ou seja, a informação que um leitor retira de um texto está dependente do conhecimento que possuí sobre o assunto a que se refere o mesmo. Para Bakhtin ${ }^{5}$, a interaçáo verbal é fundamental na língua. Ou seja, a verdadeira substância da língua não é um sistema abstrato de formas linguísticas, antes é fundamentalmente interaçáo verbal entre falantes de uma comunidade.

Este artigo objetivou em explanar aos alunos e alunas as funçóes e as demandas da Defensoria Pública da União bem como incentivá-los a escrever uma redação sobre seus

\footnotetext{
2 TRAVAGLIA, L. C. Gramática e interaçáo: uma proposta para o ensino de gramática, 2009.

3 BRASIL, 1997, p. 54.

4 LURIA, A. R.; LEONTIEV, A. N. Linguagem, desenvolvimento e aprendizagem, 2003, p. 65.

5 BAKHTIN, M. Estética da criaçáo verbal, 2003.
} 
direitos e participar do $1^{\circ}$ Concurso de redação desta instituiçãa. Considera-se, portanto, que este estudo tem uma relevância social, pois pôde contribuir de maneira significativa por suscitar novas reflexões sobre as práticas de ensino de leitura e escrita desenvolvidas no Ensino Fundamental, Médio e na EJA da Rede Estadual de Ensino de São Luís e de Paço do Lumiar - MA.

Neste sentido, os resultados da pesquisa serão socializados com o intuito de possibilitar a reflexão sobre a temática pesquisada no âmbito das políticas públicas do estado, bem como no ambiente pesquisado no qual as colaboradoras do estudo estão inseridas, constituindose numa proposta teórico-metodológica para o Ensino Fundamental, Médio e na EJA na Rede Estadual de Ensino de São Luís e de Paço do Lumiar - MA.

Comungando com esse pensamento da leitura na perspectiva da necessidade e do prazer, alguns autores subsidiam o objeto da pesquisa em questáo, tais como: Bakhtin (2003), Freire (2011), Foucambert (1997), Geraldi (2006), Jolibert (1994), Luria e Leontiev (2003), Smith $(1999)^{6}$, dentre outros, que foram fundamentais para nortear a fundamentação.

\section{METODOLOGIA}

A pesquisa foi organizada com base nos pressupostos da pesquisa qualitativa. Para Bogdan e Biklen ${ }^{7}$, as principais características de uma pesquisa qualitativa são: descrição, interesse pelo processo e náo apenas pelo resultado da pesquisa, ter o pesquisador como instrumento chave para o desenvolvimento do trabalho, questionamento do objeto de trabalho e da investigação e análise dos dados.

\footnotetext{
6 BAKHTIN, M. Estética da criaçáo verbal, 2003.

FREIRE, P. Educaçáo como prática de liberdade, 2011.

FOUCAMBERT, J. A criança, o professor e a leitura, 1997.

GERALDI, J. W. O texto na sala de aula, 2006.

JOLIBERT, J. Formando crianças leitoras. São Paulo: Artmed, 1994.

LURIA, A. R; LEONTIEV, A. N. Linguagem, desenvolvimento e aprendizagem, 2003.

7 BOGDAN, R.; BIKLEN, S. Investigaçáo qualitativa em educaçáo: uma introdução á teoria e aos métodos, 1994
} 
Paralelamente a essa pesquisa qualitativa foi realizada a pesquisa-açáo que é uma

[...] pesquisa com base empírica concebida e realizada em estreita associação com uma ação ou com a resolução de um problema coletivo e no qual os pesquisadores e participantes representativos da situaçáo ou do problema estão envolvidos de modo cooperativo ou participativo $[\ldots]]^{8}$

Segundo André a pesquisa etnográfica busca compreender a prática escolar cotidiana no sentido de descrever as atividades de sala de aula a as representaçóes dos autores escolares. Mas, vale ressaltar que não somente a descrição pela descrição trata-se de uma descrição a luz de um referencial teórico a cerca das concepçóes relacionadas ao objeto de estudo definido pelo pesquisador.

Os instrumentos utilizados no estudo foram as observaçóes e entrevistas com um roteiro (semiestruturado) aliado a aplicação de questionários a supervisora e as professoras para coletar a percepçáo, a respeito de suas dificuldades na rotina diária de sala de aula para o trabalho com a leitura e escrita dos detentos e detentas e como lidam com as dificuldades diante desse processo.

Posteriormente foram feitas as palestras sobre o tema do $1^{\circ}$ Concurso de Redação da Defensoria Pública da União com o tema "Eu tenho direito e a DPU está comigo" e depois dessas palestras os alunos participaram também de uma oficina em que aprenderam os tipos de redaçóes existentes e a solicitada no concurso e as normas cultas da língua portuguesa, posteriormente começaram a escrever suas dissertaçóes e os professores fizeram as devidas correçôes e enviaram para banca examinadora em Brasília. Foram realizadas 20 palestras em 11 escolas sendo que uma delas localiza-se no presídio feminino e masculino do nosso estado e também em escolas do Ensino Fundamental, do Médio regular e na EJA nos três turnos de ensino.

\section{RESULTADOS E DISCUSSÁO}

A participação de todos os envolvidos no processo desta pesquisa e deste concurso foi fundamental para a realização e o êxito deste. Desde o planejamento de todas as açóes,

\footnotetext{
8 THIOLLENT, M. Metodologia da pesquisa-açáo, 1985. p. 43

9 ANDRÉ, M. E. D. A. de. Etnografia da prática escolar, 1995.
} 
as oficinas de redação, as entrevistas, as dissertações e até o envio coletivo das redaçóes tivemos uma solidariedade e companheirismo de todos os atores envolvidos nesse projeto. Há a certeza de que todos esses elementos foram responsáveis para que os membros do estado do Maranhão tivessem ganhado dois prêmios em $1^{\text {o }}$ lugar na categoria da modalidade de Educação de Jovens e de Adultos.

Apesar de ter feito palestras em 11 escolas na capital e numa cidade próxima, e em escolas tradicionais em ganhar vários prêmios de literatura, teve-se uma surpresa no resultado final do concurso. Duas escolas tiveram êxito no ganho das premiaçóes em dinheiro e em certificados que marcarão para sempre a história acadêmica desses alunos. Vale destacar que o único estado do Brasil a realizar esse concurso com alunos e alunas apenados e ainda estudando no presídio foi o Maranhão, e que uma das escolas que participou das palestras e oficinas de redação localiza-se dentro de um presídio feminino em que cerca de 15 mulheres realizaram a redação e uma detenta teve sua redação escolhida para concorrer com as demais da modalidade EJA e esta alcançou o $1^{\circ}$ lugar nesta modalidade de ensino, do presídio masculino 10 homens realizaram as redaçóes e selecionamos três melhores, para concorrer mas não obtiveram premiação. Das demais escolas que participaram das palestras e oficinas de redação do Ensino Fundamental e Médio regular também não obtiveram premiação, entretanto outra escola que nos surpreendeu foi uma localizada na cidade do Paço do Lumiar da modalidade EJA um aluno adulto também alcançou o $1^{\circ}$ lugar no concurso das redaçóes.

\section{CONSIDERAÇÓES FINAIS}

A partir desta pesquisa e deste concurso pode-se perceber como a leitura e a escrita deveria fazer parte à vida dos alunos, pois eles podem conhecer vários tipos de textos e também seus direitos. Alegra-se com a realização, desenvolvimento e conclusão desta pesquisa e concurso, pois o objetivo principal foi alcançado que era explanar as funçóes da Defensoria Pública da Uniáo para os alunos e alunas e a partir desse conhecimento multiplicar essas informaçôes aos seus familiares, vizinhos e amigos, para assim fazerem uso dos seus serviços jurídicos gratuitos, além de permitir que os alunos e alunas lessem e escrevessem sobre o tema proposto.

As duas premiações em $1^{\circ}$ lugar na modalidade da Educação de Jovens e Adultos enche de alegria e entusiasmo, além disso, causa empolgaçáo e traz o desafio de continuar 
insistindo numa educação significativa para nossos alunos, principalmente daqueles que na maioria das vezes são esquecidos pela sociedade (que são os apenados) e muitas vezes nem participam de projetos educacionais quiçá de concursos e ainda ganhar um valor em dinheiro e certificados.

Concluiu-se com essa pesquisa e concurso que a leitura é considerada um dos principais meios para que os alunos possam aprimorar as leituras e suas escritas, sendo assim, a escola precisa estar atenta para essa questão, e proporcionar momentos de leituras e escritas para seus alunos, de forma lúdica, significativa e sistematizada, bem como criar condições para que seus alunos participem de concursos culturais como este demonstrado na pesquisa, para termos momentos prazerosos e conhecedores dos seus direitos, além disso, saber que a leitura e a escrita são fundamentais para exercer a cidadania.

\section{REFERÊNCIAS}

ANDRÉ, M. E. D. A. de. Etnografia da prática escolar. Campinas: Papirus, 1995.

BAKHTIN, M. Estética da criaçáo verbal. São Paulo: Martins Fontes, 2003.

BOGDAN, R.; BIKLEN, S. Investigação qualitativa em educaçáo: uma introduçáo á teoria e aos métodos. Porto (Portugal): Porto Editora, 1994.

BRASIL. Ministério da Educação. Secretaria de Educação Fundamental. Parâmetros curriculares nacionais: língua portuguesa. Brasília, DF: MEC, 1997.

FOUCAMBERT, J. A criança, o professor e a leitura. Porto Alegre: Artmed, 1997.

FREIRE, P. Educação como prática de liberdade. São Paulo, 2011.

GERALDI, J. W. O texto na sala de aula. São Paulo: Ática, 2006.

LURIA, A. R.; LEONTIEV, Alexis Nikolaevich. Linguagem, desenvolvimento e aprendizagem. São Paulo: Ícone, 2003.

SMITH, F. Leitura significativa. Porto Alegre: Artmed, 1999. 
THIOLLENT, M. Metodologia da pesquisa-ação. São Paulo: Cortez, 1985.

TRAVAGLIA, L. C. Gramática e interação: uma proposta para o ensino de gramática. 14. ed. São Paulo: Cortez, 2009. 